\title{
Carbon Dioxide Capture and Application Technology
}

\author{
Jiamin Jin \\ Shanghai Research Institute of Materials, Shanghai, China \\ Email:jjm82@163.com
}

How to cite this paper: Jin, J.M. (2021)

Carbon Dioxide Capture and Application

Technology. Journal of Materials Science and Chemical Engineering, 9, 27-37.

https://doi.org/10.4236/msce.2021.94004

Received: February 2, 2021

Accepted: April 17, 2021

Published: April 20, 2021

Copyright $\odot 2021$ by author(s) and Scientific Research Publishing Inc. This work is licensed under the Creative Commons Attribution International License (CC BY 4.0).

http://creativecommons.org/licenses/by/4.0/

\begin{abstract}
This paper focuses on the supplementary explanation and modification of the six published articles for 8 aspects. Including the energy storage reaction and storage index, push rod type electric furnace, the production of sponge iron and lime is accompanied by the production of nitrogen-free gas, to promote the use of gas in the countryside, lime is cycliceally used to capture carbon dioxide in the flue, to make full use of natural resources and some problems to be studied in industrial production.
\end{abstract}

\section{Keywords}

Carbon Dioxide, Storage Reaction and Storage Index CCS, CCSE, SSE

\section{Introduction}

The warming of the earth and the frequent occurrence of the extreme weather, have seriously affected the survival and life of human beings. There was a great deal of anxiety. The United Nations has held many meetings, especially in Paris. Scientists generally believe that the earth is warming as a result of massive emissions of carbon dioxide from industrial production. As a result, the capture and storage of $\mathrm{CO}_{2}$ on a global scale, known as the Carbon Capture and Storage-CCS technical route, has become the focus of research by many scientists and the strategy of governments. Zhang Dongxiao, director of the Clean Energy Research Institute at Peking University, said that the CCS (Carbon Capture and Storage) technical route could become the single largest carbon reduction technology in the world. The UN's International Energy Agency (IEA) has repeatedly stressed that the CCS technical route remains an important solution for reducing greenhouse gas emissions. It calls for 200 CCS projects globally to be operational by 2020 and 3000 by 2050 . Between 2015 and 2050, the world should 
capture and store 120 billion tonnes of carbon dioxide. The CCS technical route from an American power plant seems to be the only one that can save the earth.

Since 2016, the author has published 6 articles on the use of captured carbon dioxide storage to save the earth in domestic and foreign journals. The contents involve climate change, energy, environmental protection, and other major issues. This paper aims to further clarify the author's point of view, it is hope to arouse people's attention

\section{There Are Many Problems with the CCS Technical Route}

In previous articles [1]-[6], the author has repeatedly pointed out that there are a number of problems with the current CCS route being rolled out globally. Such as high cost, limited burial places, there is a carbon dioxide leakage of safety risks.

Experts believe that the only way out for CCS technology is through a combination of storage and application. If we have buried all the captured carbon dioxide, it would be economically unbearable. However, the purification application of carbon dioxide is a worldwide problem, which has not been solved yet. The authors argue that even if this puzzle is solved, its application may be limited, so the CCS technical route is a dead end. Although the internationally recognized CCS technical route is still in the research stage, 56 CCS projects are already operating or planned around the world. China also has 11 CCS projects planned or in operation. It can be seen that people are anxious about the warming of the climate.

\section{Carbon Capture and Stored Energy-CCSE and Smoke Stored Energy-SSE Technical Route}

The author first proposed CCSE in 2016 and SSE in 2020. CCSE or SSE technology is a technology that can convert electrical energy into chemical energy and then store and apply it.

It's theory is that carbon gasification is an endothermic or energy-storage reaction $\left(\mathrm{C}+\mathrm{CO}_{2}=2 \mathrm{CO} \Delta \mathrm{H}^{0}{ }_{298 \mathrm{k}}=+162,297 \mathrm{~kJ} / \mathrm{mol}\right)$. This is a simple chemical reaction. It has been used in industrial production for more than 100 years. Such as gas generators, blast furnaces making iron, etc.

The combination of storage and application is the only feasible route for CCSE or SSE. The climate can be controlled by adjusting the proportion of storage and application. SSE different from CCSE is that the smoke is applied directly. SSE saves an expensive capture cost. The deficiency of SSE is that there is a large amount of nitrogen in the gas, the calorific value is lower, if it is used cyclically, the calorific value is getting lower and lower, and the production process is unstable. Therefore, it is necessary to improve and stabilize carbon dioxide content in smoke by simple centrifugation-gravity method. If the cost of using compression separation to capture carbon dioxide can reach $\$ 25 / \mathrm{t}$, as announced by the Massachusetts Institute of Technology, and the cost of producing carbon 
monoxide per meter is only $\$ 0.025$, it is entirely acceptable.

The mechanism of carbon catalysis gasification has been studied for more than 50 years. CCSE or SSE technique is the extension of carbon gasification catalysis mechanism research.

\section{The Energy Storage Reaction and the Energy Storage Index-ZN}

There are two common endothermic reactions; namely

$$
\begin{array}{cc}
\mathrm{C}+\mathrm{CO}_{2}=2 \mathrm{CO} & -162297 \mathrm{~kJ} / \mathrm{kg} \cdot \mathrm{mol} \\
\mathrm{C}+\mathrm{H}_{2} \mathrm{O}=\mathrm{H}_{2}+\mathrm{CO} \quad-131381 \mathrm{~kJ} / \mathrm{kg} \cdot \mathrm{mol}
\end{array}
$$

Both of these reactions are endothermic or energy-storing reactions. These two reactions exist in the gas generator furnace.

Equation (1) is the carbon gasification reaction, also known as the Bouduard reaction. It is a very important reaction. Many industrial products depend entirely on this reaction, such as $\mathrm{Fe}, \mathrm{Cu}$ etc.

The heat released by the combustion of carbon monoxide from the gasification reaction is the heat stored.

$$
2 \mathrm{CO}+\mathrm{O}_{2}=2 \mathrm{CO}_{2}+570865 \mathrm{~kJ} / \mathrm{kg}
$$

The energy storage index $\mathrm{ZN}$ is the ratio of the energy stored by gas after the chemical reaction to the energy consumed during the chemical reaction, which is used to measure the energy storage efficiency of different carbonaceous materials。

For carbon gasification reaction, the storage value is compared with the consumption value, namely $(3) /(1), 570,865 / 162,297=3.517$, deduct about $3 \%$ of the furnace wall heat loss, The energy storage index $\mathrm{ZN}$ of carbon gasification reaction $\mathrm{Is} \mathrm{ZN}=3.4$. This data shows that the energy stored after gasification is 3.4 times that consumed. It is known that the direct combustion to indirect combustion, especially compared with the rural hearth, can significantly improve the thermal efficiency, thermal efficiency can completely offset the heat loss of the furnace wall, so the electric heating gas generator can be called zero energy electric heating gas generators. In terms of economy, it is very economical to use electric heating furnace to produce gas.

The raw materials for the production of gas always contain water, and $\mathrm{C}+\mathrm{H}_{2} \mathrm{O}=\mathrm{CO}+\mathrm{H}_{2}$ is also an endothermic or energy-storage reaction.

$$
\mathrm{H}_{2}+1 / 2 \mathrm{O}_{2}=\mathrm{H}_{2} \mathrm{O} \quad-285800 \mathrm{~kJ} / \mathrm{mol} \cdot \mathrm{kg}
$$

$[(4)+2 / 1(3)] /(2)$, namely $\mathrm{ZN}=[285,800+285,432] / 131,381=4.35$.

When $\mathrm{ZN}>4.0$ and the thermal efficiency of the thermal power plant increases to $50 \%$ (the highest thermal efficiency of the thermal power plant is $46 \%$ at present), the energy stored in the gas produced by valley electricity can fully meet the energy required for peak electricity generation, which alone can save half of the thermal power coal consumption. The reduction in carbon dioxide emissions by nearly half is staggering, I should say. On this basis alone, the 
amount of gas that needs to be stored may be small.

The United States and China account for 52\% of global carbon dioxide emissions, China accounted for 35\%. If China and the United States can work together, so it can save half of the coal consumption of the thermal plant, the problem of global warming will maybe solve.

Energy storage index $\mathrm{ZN}=3.52$ is very reliable and important data. The $\mathrm{ZN}$ tells you very clearly, although electricity is in short supply around the world, there are two things that people should understand. First, it is not willing to use electricity to produce gas, which may be that many scientists so far have not proposed the electric gas generation furnace thought concerns. This concern now seems unnecessary. Second, because of the $\mathrm{ZN}>4$, people would naturally think that the first use of electricity in lighting, electrical machinery, and so on seems unreasonable. Electricity shall first be supplied to a zero-energy electric heating gas generator. It can both consume large amounts of carbon dioxide, plastic waste, eliminates white pollution and the ability to control the climate warming that people are so worried about.

\section{Develop Electric Gas Generator Energetically}

The author thinks that the development of electric gas generator is based on:

1) $\mathrm{CO}_{2}$ buried as waste in CCS technical route becomes the main raw material for gas production in CCSE or SSE technical route. The purpose of climate control can be achieved by adjusting the proportion between storage and application of gas.

2) CCSE or SSE technical routes can consume a lot of firewood, waste plastic, eliminate the white pollution that people are so worried about, and protect the environment.

3) The $\mathrm{ZN}=3.52$ for the carbon gasification reaction in the electric heating gas generator is very economical.

The electric gas generator is the only major device in CCSE or SSE, but it is an innovative device that has not been seen so far. It is actually an electric heating furnace. In addition to the generator, the ancillary equipment is the compressor and number of storage gas bags or tanks.

The power of the furnace depends on the output. It takes about $1 \mathrm{kwh}(1.06$ $\mathrm{kwh}$ ) to produce $1 \mathrm{~m}^{3}$ of gas, and $1000 \mathrm{~kW}$ of power to produce $1000 \mathrm{~m}^{3}$ of gas an hour.

The type of furnace may be varied, such as vertical, horizontal, converter etc.

The converter type is widely used in cement and sponge iron production, its advantage is that the furnace charge in the furnace is constantly turned back, so it reacts fast. For easily broken processing of raw materials, such as coal, firewood, plastic and so on, it is more appropriate.

The ancient tunnel kiln type electric gas generator has the advantages of mature technology, simple structure, small investment and small operation energy consumption, among which the biggest advantage is that raw materials such as 
firewood, garbage and corpse do not need to be processed and can be directly put on the kiln car. Its disadvantage is that the reactants such as coal are fixed on the kiln boat and the reaction speed is slower.

Push-rod electric gas generator (Figure 1) should be the simplest type of furnace and minimum investment. Furnace body can be large or small. It can be generalized in the countryside.

A $50 \mathrm{kw}$ electric stove; can produce $1200 \mathrm{~m}^{3}$ of gas a day, can meet the needs of thousands of farmers cooking.

No matter which type of furnace is used, they should have 4 things in common.

1) It is that the furnace chamber or furnace body must be sealed;

2) The flow direction of raw materials and $\mathrm{CO}_{2}$ must be the same from low temperature to high temperature;

3) It must be operated at positive pressure to prevent air from entering the furnace;

4) It must have a good measuring instrument, according to the gas composition check results, adjust the $\mathrm{CO}_{2}$ intake and furnace charge.

Because that the composition of raw materials, such as firewood can not be stable. Therefore, a pulverized coal injection device should be installed at the end of the furnace. According to the analysis results of the gas composition, the $\mathrm{CO}_{2}$ content in the gas should be guaranteed under $2 \%$ to ensure the stable calorific value of the gas.

\section{Sponge Iron and Nitrogen-Free High Calorific Clean Gas are Produced Simultaneously by Using Electric Heating Gas Generator}

At present, the world's production of sponge iron is between 50 and 60 million tons. Most of them are used to make steel in electric furnaces. Part of it is used in powder metallurgy production. There are more than 20 methods to produce sponge iron. However, converter and the tunnel kiln is still the main method. Both completely rely on carbon gasification reaction to produce sponge iron (C $\left.+\mathrm{CO}_{2}=2 \mathrm{CO}, \mathrm{CO}+\mathrm{FeO}=\mathrm{Fe}+\mathrm{CO}_{2}\right)$.

Figure 2 is the flow velocity and composition of gas released from the reduction

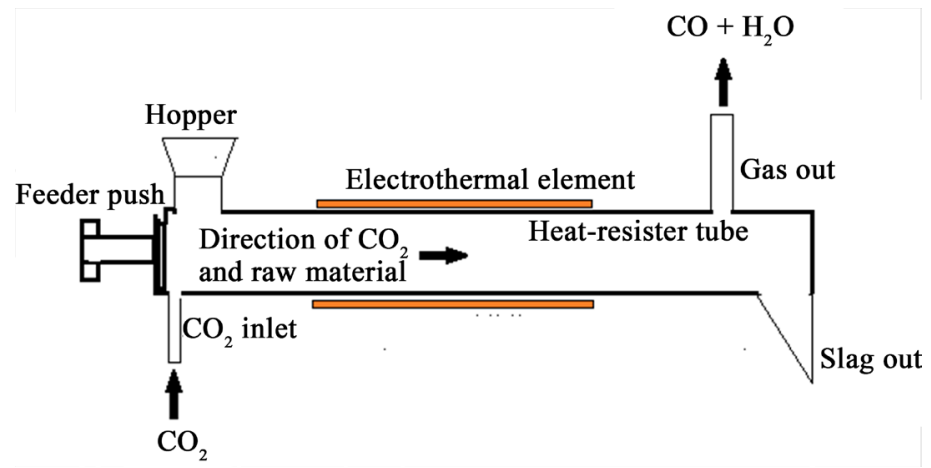

Figure 1. Push-rod type electric gas generator diagram. 


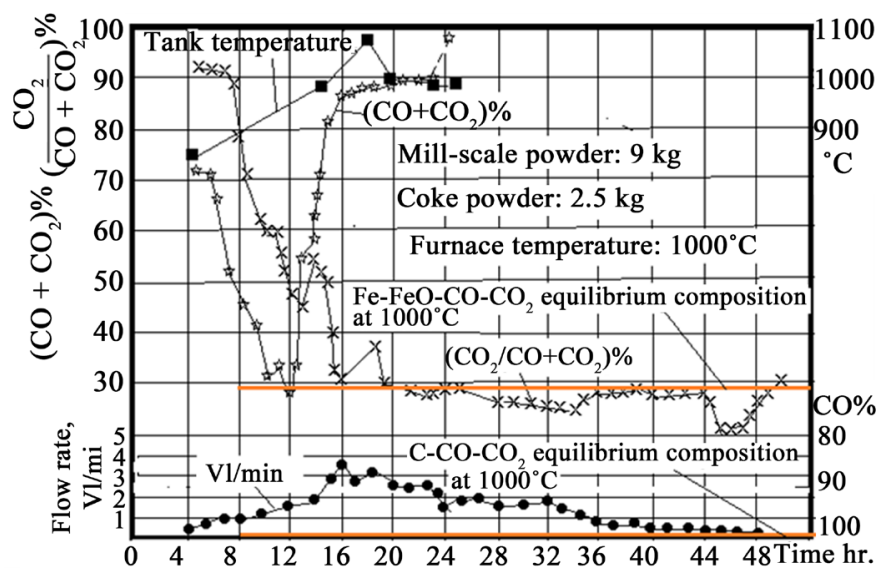

Figure 2. Gas velocity and composition released from the reduction reaction tank.

reaction tank. The $\mathrm{CO}$ content in the gas is about $65 \%$, and the $\mathrm{CO}_{2}$ content is about 35\% (Different reduction stages have different gas compositions). When we add small solid carbon outside the reaction tank and completely convert 35\% $\mathrm{CO}_{2}$ to $\mathrm{CO}$, we can get $100 \% \mathrm{CO}$ gas with nitrogen-free almost. Because that in the beginning, the reaction tank is filled with iron oxide and carbon powder. There is small air left and it's expelled very quickly at the beginning of the reaction. So we get nitrogen-free high calorific value clean gas. The result is similar to using high purity oxygen to produce gas.

According to the chemical reaction formula $\left(\mathrm{Fe}_{2} \mathrm{O}_{3}+3 \mathrm{C}=2 \mathrm{Fe}+3 \mathrm{CO}\right)$, for every 1 ton of sponge iron produced, $600 \mathrm{~m}^{3}$ of high purity clean gas can be obtained. Now, however, the current production is not like this at all.

The $\mathrm{CO}$ released from the reduction reaction tank is burned into $\mathrm{CO}_{2}$ in the furnace, then it is expelled from the furnace with smoke. At 50 million tons of sponge iron a year, we throw away 30 billion $\mathrm{m}^{3}$ of nitrogen-free quality gas every year.

Global iron ore production was 2.163 billion tonnes in 2017. Calculated at an average grade of $48.8 \%$, the concentrates should have 10.6 billion tons. It contains 306 million tons of oxygen. According to the current production technology, after smelting, these oxygen are expelled as $\mathrm{CO}_{2}$ form, which is nearly 420 million tons. Oxygen in iron ore is not being used. On the contrary, it pollutes the air. The author thinks that man has wasted valuable natural resources again.

There are many advantages to producing sponge iron and gas simultaneously. Such as: The iron and oxygen in iron ore are used, reduced $\mathrm{CO}_{2}$ emissions, obtained quality nitrogen-free gas, reduced coke consumption, the cost of production has fallen considerably. This approach has strong competitiveness.

\section{Lime and Nitrogen-Free High Calorific Value Clean Gas are Produced Simultaneously by Make Use of Electric Heating Gas Generator}

$\mathrm{CaO}$ (commonly known as lime) is the main ingredient in cement, and its content ranges from 64 to $67 \%$. Calcined limestone releases $44 \%$ of $\mathrm{CO}_{2}$, that is, a 
ton of calcined limestone releases 440 kilograms of $\mathrm{CO}_{2}$. In 2016, the global output of cement is 5 billion tons, China is 2.5 billion tons, based on $65 \%$ content, $\mathrm{CaO}$ is 3.25 billion tons, limestone consumption is 5.8 billion tons, and the carbon dioxide emitted is 2.55 billion tons. According to the calculation that one ton of $\mathrm{CO}_{2}$ can produce $1000 \mathrm{~m}^{3}$ of carbon monoxide, 2.55 billion tons of $\mathrm{CO}_{2}$ can produce 2.55 trillion $\mathrm{m}^{3}$ of nitrogen-free clean gas with a high calorific value. At present, 2.55 billion tons of carbon dioxide is all released into the sky, and valuable natural resources are once again being wasted by humans.

According to the following reaction:

$$
\begin{gathered}
\mathrm{CaCO}_{3}=\mathrm{CaO}+\mathrm{CO}_{2} \quad \Delta \mathrm{H}_{298 \mathrm{k}}^{0}=+177.4 \mathrm{~kJ} / \mathrm{mol} \\
\mathrm{C}+\mathrm{CO}_{2}=2 \mathrm{CO} \quad \Delta \mathrm{H}_{298 \mathrm{k}}^{0}=+162.297 \mathrm{~kJ} / \mathrm{mol} \\
\mathrm{CaCO}_{3}+\mathrm{C}=\mathrm{CaO}+2 \mathrm{CO} \quad \Delta \mathrm{H}_{298 \mathrm{k}}^{0}=+339.697 \mathrm{~kJ} / \mathrm{mol} \\
2 \mathrm{CO}+\mathrm{O}_{2}=2 \mathrm{CO}_{2} \quad \Delta \mathrm{H}_{298 \mathrm{k}}^{0}=-570.865 \mathrm{~kJ} / \mathrm{mol}
\end{gathered}
$$

The energy storage index $\mathrm{ZN}$ is calculated; $\mathrm{ZN}=(7) /(6)=570.865 / 339.697=$ 1.68. This 1.68 means that one energy is consumed and 1.68 energy is stored, so it is very economical to produce nitrogen-free high calorific clean gas when producing lime.

Figure 3 shows the cyclic reaction of capturing $\mathrm{CO}_{2}$ from flue gas with $\mathrm{CaO}$ and producing nitrogen-free high calorific clean gas with $\mathrm{CO}_{2}$ from limestone decomposition.

\section{Gas Is Used in the Vast Countryside}

The countryside is a vast world, as far as the eye can reach.

Every plant and animal on the ground, growing day and night, has stored a great deal of energy, which people should make full use of.

As shown in Figure 1, a push-rod type gas generator is most suitable for general promotion in rural areas. A small $20 \mathrm{KW}$ electric stove can produce $480 \mathrm{~m}^{3}$ of gas per day, which can supply thousands of farmers. It's also very economical.

Rural coal gasification, not only the use of resources, and the protection of

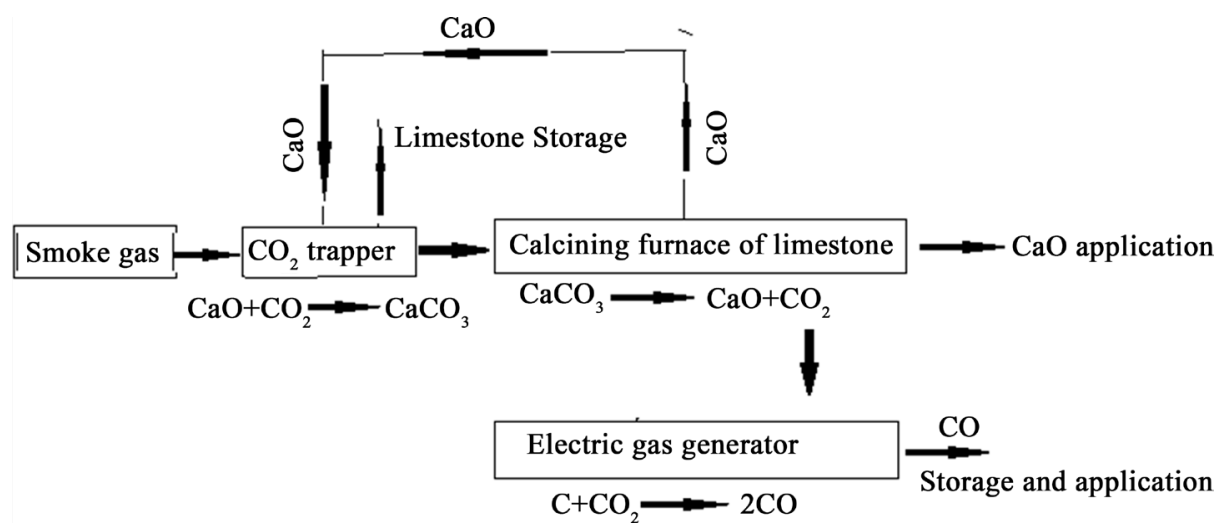

Figure 3. Cyclic reactions between $\mathrm{CO}_{2}$ capture by using $\mathrm{CaO}$ and gas production. 
resources, and the protection of the environment. Beautiful scenery, heaven on earth.

\section{Power Supply}

The International Energy Agency (IEA) has called for the capture and bury of 120 billion tonnes of $\mathrm{CO}_{2}$ global between 2015 and 2050. That's an average of 3.4 billion tons a year, it is about a tenth of annual emissions of 33 billion tons (2018). Adopting the CCSE technology route to convert 3.4 billion tons of $\mathrm{CO}_{2}$ into $\mathrm{CO}$ requires 3.4 trillion $\mathrm{kwh}$, which can produce 3.4 trillion $\mathrm{m}^{3}$ of $\mathrm{CO}$. It must be considered that the CCSE technical route must be a combination of storage and application, at the same time, considering the price of electricity $(0.72$ yuan $/ \mathrm{kwh} \mathrm{rmb})$ and the price of gas $\left(2.5 \mathrm{yuan} / \mathrm{m}^{3}\right), 2.5 / 0.72=3.47$, that is, the cost of applying $1 \mathrm{~m}^{3}$ gas can offset the cost of storing $3.47 \mathrm{~m}^{3}$ of gas. Because each country's coal electricity price is different, afore-mentioned are only for reference. To set the application to storage ratio at $1 / 3$, that should be feasible. Thus, the amount of $\mathrm{CO}_{2}$ required for gasification is 4.8 billion tons. The amount of electricity used is 4800 billion kwh. The production of CO is 4.8 billion $\mathrm{m}^{3}$, of which 3.4 billion $\mathrm{m}^{3}$ are for storage and 1.4 trillion $\mathrm{m}^{3}$ for application.

Today, the world's electricity generation is 25551.28 billion kwh, China is 6495.14 billion kwh, accounting for 1/4, the United States 4281.74 billion kwh, accounting for $16.8 \%$. According to this, China's electricity generation alone can fully meet the requirements of 4.8 trillion degrees. But the author still thinks that first-time electricity should be the electric gas generator. Lighting, electric machinery and so on should be secondary electricity. This not only uses a large number of resources on the ground, protects the environment, controlling the climate, but also protects underground resources.

\section{Several Issues to Be Discussed}

According to the energy storage index $\mathrm{ZN}=3.4$ of carbon gasification reaction, we consider inevitably that there are many problems worth studying in the current industrial production.

\section{1) Pumped storage power station}

The purpose of energy storage is achieved to use valley electricity to lift the water from the lower reservoir to the upper reservoir and convert mechanical energy into potential energy.

There are many such pumped storage plants around the world. China's current installed capacity is 27.73 million $\mathrm{kw}$, surpassing Japan and becoming the world's largest. It accounts for less than $0.01 \%$ of the country's total installed capacity.

The thermal efficiency of the pumped storage power station is $70 \%$ and $\mathrm{ZN}$ is a negative value, which is compared with the electric gas generator of $\mathrm{ZN}>4$. Obviously, it is more reasonable to build an electric gas generator.

\section{2) Garbage incinerator and cinerator}


Currently, garbage incinerators and cinerators are widely used worldwide. Firewood, plastic, rubber, seaweed, animal carcasses and so on, which store a large of energy, are burned by a torch, which not only consumes a lot of fuel, wastes a large of energy, but also pollutes the environment, which is a very unreasonable measure.

For example, Plastic pollution is already a very serious problem. Four billion tons of plastic are already buried in the ground or stacked in nature. Ten million tons of tiny plastic particles enter the ocean every year, there are now 150 million tons of plastic in the ocean.

According to the molecule structural formula, the calculation results show that $1 \mathrm{t}$ of $\mathrm{PE}$ or PP type plastic reaction with $\mathrm{CO}_{2}$ at high temperature, can produce $4800 \mathrm{~m}^{3} \mathrm{CO}$ and $\mathrm{H}_{2}$ clean gas.

So a lot of energy has been wasted by humans.

A 50-kilogram animal carcass can produce about $120 \mathrm{~m}^{3}$ of high-heat clean gas. Worldwide, about 150,000 people die each day. If used to produce gas, 18 million $\mathrm{m}^{3}$ of high-calorific value clean gas could be produced each day.

\section{3) Full use of natural resources}

As mentioned earlier, gas can be produced at the same time as sponge iron, $1 \mathrm{t}$ of sponge iron and $600 \mathrm{~m}^{3}$ of nitrogen-free high calorific clean gas. Gas can also be produced when lime is produced at the same time. One ton of limestone can simultaneously produce $560 \mathrm{~kg}$ of $\mathrm{CaO}$ and $440 \mathrm{~kg}$ or $440 \mathrm{~m}^{3}$ of nitrogen-free or low-nitrogen high calorific clean gas. At present, however, only $\mathrm{Fe}$ and $\mathrm{CaO}$ are extracted, and oxygen in iron ore and carbon dioxide in limestone are discarded in total and it pollutes the air at the same time.

Global cement production is 5 billion tons (China 2.5 billion tons). Based on $65 \% \mathrm{CaO}$ content in cement, 5.8 billion tons of limestone was consumed. During calcination, 2.55 billion tons of $\mathrm{CO}_{2}$ are released. Global iron ore production was 2230.4 billion tonnes. According to the average iron content of $48.8 \%$, the concentrate fines $\left(\mathrm{Fe}_{2} \mathrm{O}_{3}\right)$ is 1.55 billion tons. The oxygen content in iron ore is 470 million tons. The amount of $\mathrm{CO}_{2}$ released after smelting is 640 million tons. Thus, the amount of $\mathrm{CO}_{2}$ abandoned from cement and steel production alone is 3.2 billion tons. It accounts for one-tenth of the 33 billion tonnes of $\mathrm{CO}_{2}$ emitted annually. Endless development of natural resources, and a large amount of waste of resources, this is the tragedy of human beings.

\section{4) Making use of lime to capture $\mathrm{CO}_{2}$}

As you can see from the literature, the methods of capturing $\mathrm{CO}_{2}$ include chemical assimilation, physical adsorption, physical-chemical adsorption, membrane separation and cryogenic separation. And physical assimilation and chemical adsorption it is relatively mature and has small-scale industrial installations. In the CCS technical route, capture cost accounts for $2 / 3$ of the total capture and storage cost. It means the capture cost is very high.

As shown in Figure 3, the author thinks that there are several advantages of using lime to capture carbon dioxide. 
a) $\mathrm{CaO}+\mathrm{CO}_{2} \rightarrow \mathrm{CaCO}_{3}$ reaction is an exothermic reaction, which does not require additional heat.

b) The $\mathrm{CaO}$ can be recycled.

c) The requirement of purity of $\mathrm{CO}_{2}$ in smoke before and after capture is not strict.

d) Compared with other capture methods, using lime to capture carbon dioxide, investment and operating costs may be the lowest.

e) Cement production costs can be significantly reduced.

etc.

The flue gas passes through an iron drum. The size, rotation speed and reaction temperature of the drum are determined by the experiment.

\section{5) Natural Balance and Balancing Point}

The growth of plants and animals on the earth is interdependent. The ppm of carbon dioxide in the air should have a "balance point". If carbon dioxide emissions are greater than plant growth requirements, As a result, the climate is warming.

If the emissions are less than the equilibrium value, it is not conducive to plants' growth, plants will also die because of lack of carbon dioxide. At present, global electricity generation can convert $75 \%$ of carbon dioxide emissions into carbon monoxide for use and storage. But this is clearly unnecessary and undesirable.

The realization of natural balance requires a "balance point". Once a "balance point" is found, the amount of $\mathrm{CO}_{2}$ to be captured can be determined.

\section{Conclusions}

1) Thermal power plants should use lime or gravity-centrifugal method to capture carbon dioxide in the flue, which can significantly reduce capture costs.

2) Electric gas generators should be used in the garbage incinerator. Use electricity and carbon dioxide to produce high-calorie gas. Increase renewable energy, protect resources, protect the environment and eliminate white pollution.

3) When producing lime, the gas should be produced at the same time, which can make full use of natural resources, reduce pollution and reduce the cost of lime production.

4) When sponge iron is produced, the gas should be produced at the same time, which can make full use of natural resources and realize carbon-free iron making.

5) Electricity transmission is changed to gas transmission, which can save energy consumption, reduce electricity price and benefit the country and the people.

The above five conclusions, the author believes that it is only general knowledge, technical difficulties do not exist. There is no problem with the electricity supply. The author thinks that if these five measures can be realized on a global scale, perhaps climate warming, environmental pollution, energy depletion, and 
so on can be solved or remissioned.

\section{Conflicts of Interest}

The author declares no conflicts of interest regarding the publication of this paper.

\section{References}

[1] Jin, J.-M. (2016) Power Generation Technology Using $\mathrm{CO}_{2}$ Capturs Energy Storage. Power \& Energy, 37, 495-497.

[2] Jin, J.-M. (2017) Make Use of Capture $\mathrm{CO}_{2}$ for Storage Energy and Carbon Reduction Emission. Guangzhou Chemical Industry, 45, 42-44.

[3] Jin, J.-M. (2017) Making Use of Capture $\mathrm{CO}_{2}$ for Storage Energy and Carbon Reduction Emission. Journal of Low Carbon Economy, 6, Article ID: 21550.

[4] Jin, J.-M. (2019) Making Use of Capture $\mathrm{CO}_{2}$, Coal and Firewood to Produce Gas. Journal of Low Carbon Ecomomy, 8, 103-107.

[5] Jin, J.-M. (2020) Making Use of $\mathrm{CO}_{2}$ Capture for Saving Earth and Human-A comparison of "Carbon Capture and Storage-CCS" and "Carbon Capture and Stored Energy-CCSE”. Global Journal of Human Social Science Research, 20, 17-20.

[6] Jin, J.-M. (2020) Technology of Tunnel Kiln Type Electric Gas Generator Development by Using Captured $\mathrm{CO}_{2}$ and Garbage Plastics. Power \& Energy, 41, 84-87. 